The first, No. 4, is on "Miocene Anthracotheriidæ from East Africa", by D. G. MacInnes (pp. $24+$ 4 plates, 1951). The author comments on the fact that most of the East African fossil material is fragmentary, possibly as the result of scavenging animals attacking the dead bodies. The presence of a wellpreserved skull and also some fragments of others enables the author to establish satisfactorily, and in some detail, a new species Brachyodus aequatorialis. The material included some limb bones and metapodials which, while not directly associated with the skulls, can reasonably be attributed to the same, or a closely allied species. Further information on Hyoboops africanus is also provided.

The second, No. 5, by W. E. Le Gros Clark and D. P. Thomas, is based on specimens of "The Miocene Lemuroids of East Africa" (pp. $20+3$ plates, 1952). The material includes mandibular and maxillary fragments, a brain case and an endocranial cast. It all belongs to the sub-family Galaginæ and to the genus Progalago. The name was given because, when the type species $P$. dorce was described by D. G. MacInnes, it was considered that it represented a group from which the modern Galago might well have been derived. The paper adds considerably to our knowledge of the type species and also describes two further species of the genus, and the authors comment that none of the new evidence is contrary to the suggestion made with regard to the relationship of the genus with Galago. The plates accompanying both papers are of a high quality and very well reproduced.

\section{Radioactive Starch and Hexose Sugars}

THE preparation of radioactive starch, glucose and fructose from tobacco leaves after assimilation of ${ }^{14} \mathrm{CO}_{2}$ has been described by $\mathrm{H}$. K. Porter and $\mathrm{R}$. V. Martin (J.Exp. Bot., 3, 9, 326; 1952). In the photosynthesizing process, the experimental control of which is described, at least 80 per cent of the ${ }^{14} \mathrm{CO}_{2}$ supplied appeared in the leaves as starch and sugar and more than 80 per cent of the radioactivity was accounted for in these carbohydrates. Small amounts of radioactive carbon were also found to be incorporated in the protein, cellulose, hemicellulose and polyuronide components of the leaf.

3-Indolylacetonitrile : an Important Plant Hormone

INVESTIGATIONS of the recently discovered and important plant growth hormone, 3-indolylacetonitrile, and of 3 -indolylacetaldehyde (reported to be present in plants), and both now available as pure synthetic substances, are described by J. A. Bentley, S. Housley and A. S. Bickel (J. Exp. Bot., 3, 9, 393, $406 ; 1952)$. As measured by their effects on cellelongation in the coleoptile of Avena, 3-indolylacetaldehyde is considerably less active than 3-indolylacetic acid. An acidic substance is produced by the aldehyde during the period of assay, and in some experiments the aldehyde's activity could be accounted for on the assumption that it is transformed into 3-indolylacetic acid. Other evidence indicates that the aldehyde itself is either inactive or inhibitory. The nitrile, which is considerably more active than 3-indolylacetic acid, shows little production of acid during the period of assay. As the nitrile is destroyed by treatment with alkali but not with acid, the authors consider that earlier work on the identification of auxins in plants by their acid and alkali sensitivity should be re-examined. By using the Avena straight-growth test, in which the nitrile shows activity, evidence has now been obtained that it is present in various members of the Cruciferæ. Transport of the nitrile, like that of the acid, is polar, but it is considered that the nitrile can reach the growing cells as easily, if not more so, than the acid -a finding that is important in attempts to postulate the mechanism of nitrile action. The nitrile is less active in the Avena curvature test than the acid, and is inactive in the pea curvature and straight-growth tests except at high concentrations. It is inactive or only slightly active in the inhibition of lateral buds, in the inception of roots, and in petiole abscission at the concentrations tested. It is also less active than the acid in root inhibition in cress, but about as active in Avena. It is of about the same activity as the acid in the development of parthenocarpic fruit and the stimulation of cambial activity.

\section{Total Eclipse of the Sun on June 30, 1954}

A supplement to the "American Ephemeris and Nautical Almanac" for 1954 has been issued by the U.S. Naval Observatory, entitled "Total Eclipse of Sun, June 30, 1954" (pp. 42. Washington, D.C. : Govt. Printing Office, 1952; 40 cents). It is designed primarily for use along the path of the total phase of this eclipse, which will be visible in the United States, Canada and Greenland; but data are also given for the Atlantic Ocean and Europe. The maps provide local circumstances of the eclipse for all places within the limits of the eclipse region extending from the southern limit of the eclipse to lat $73^{\circ} \mathrm{N}$., and from long. $170^{\circ} \mathrm{W}$. to $80^{\circ} \mathrm{E}$. Two tables givo the necessary data for finding the position of the central line at various heights above sea-level and in the ionosphere up to $300 \mathrm{~km}$., and also the duration of totality on the central line and the width of the path, at the earth's surface and at heights ranging from 100 to $300 \mathrm{~km}$. The "American Ephemeris and Nautical Almanac" for 1954 gives a map for the complete eclipse area and also the Besselian elements and other usual eclipse data not given in the supplement, including an example of the calculation of the circumstances of the eclipse for a given place.

\section{Catalogue of Horrebow Star-Pairs for the determ-} ination of Northern Latitudes

A CATALOGUE of star-pairs for northern latitudes from $55^{\circ}$ to $70^{\circ}$ for astronomic determination of latitudes by the Horrebow-Talcott method has been compiled by Pentti Kalaja (Suomen Geodeettisen Laitoksen Julkaisuja, No. 41. Pp. 191. Helsinki : Finnische Geodätischen Institute, 1952). The stars of Horrebow-pairs appearing in this catalogue have been selected from the "General Catalogue of 33,342 Stars for the Epoch 1950", by Benjamin Boss, and in the selection of the stars certain principles have been observed, among which the following may be noticed. The right ascensions of the stars must lie between $17 \mathrm{~h}$. and $24 \mathrm{~h}$. and their declinations between $30^{\circ}$ and $85^{\circ}$. Stars of magnitudes between 3 and 7 only are admitted; experience has shown that it is not advantageous to use very bright stars, although their declinations are generally determined with great accuracy. The parallax of the star used must be less than $0.05^{\prime \prime}$ and the probable error of the declination must be smaller than $\pm 0.40^{\prime \prime}$. In addition, double stars, of which the distance from each other lies between $0 \cdot 1^{\prime \prime}$ and $6^{\prime \prime}$ and the difference in magnitude is less than $3 \mathrm{~m}$., have been rejected. Double stars which have circular or elliptical motion, and those which have peculiarities in proper motion, have also 